\title{
THE GREAT DIVIDE: ECONOMIC COMPLEXITY AND DEVELOPMENT PATHS IN BRAZIL AND SOUTH KOREA
}

\author{
Gustavo Britto, João Romero, Elton Freitas e Clara Coelho
}

\begin{abstract}
This paper expands the product space methodology to analyse the relationship between structural change, economic complexity and distinct paths of economic development. To do so, it presents product space networks for each decade since the 1960's and analyses revealed comparative (dis)advantages indictors for Brazil and South Korea from the 1960s to 2000s. The exercise renders two main findings. First, it shows significant changes of the international division of labour and trade as well as each of the countries' trade evolution in terms of comparative advantages in products classified by technological-intensity. Secondly, the indexes of revealed comparative advantage and disadvantage to analyse economies' diversification, bottlenecks, and complexity show that although having similar initial per capita GDPs, South Korea achieved faster growth than Brazil by specialising early on higher complexity, technology-intensive goods and services. This shows that growth and development is highly path dependent and contingent on production complexity.
\end{abstract}

Acknowledgements: The authors are grateful for financial support received from FAPEMIG, CAPES and CNPq. This paper received the first place in a nationwide prize awarded by the Confederação Nacional da Indústria - (CNI) in 2015 for papers on the Brazilian Industry.

JEL: 014; O19; O57; F14.

Aréa ABEIN: 1 


\section{The Great Divide: Economic Complexity and Development Paths in Brazil and South Korea}

\section{Introduction}

The relationship between different economic structures and distinct paths of economic development have long been recognised in the economic literature, in particular from the 1950s onwards, with the rise of development economics. According to the structuralist literature that flourished in this period, economic development is inextricable from changes in the sectoral composition of production (e.g. e.g. Lewis, 1955; Kuznets, 1966; Kaldor, 1966; Hirschman, 1958; Prebisch, 1962; Furtado, 1964). In this approach, development and growth depend on moving production towards sectors that produce goods that are complex and have high value added, in expense of sectors that produce simple, low value-added goods.

More recently, a number of studies have emphasised the importance of accumulating capabilities that allow the production of more sophisticated goods, arguing that accumulating capabilities is a necessary condition for structural change (e.g. Lall, 1992; Archibugi and Coco, 2005). In this literature, capabilities are associated with non-tradable inputs, i.e. tacit knowledge, and a fair share of the works in this approach has sought to identify and measure capabilities across countries or industries. However, this is an extremely complex task.

Following this tradition, Hidalgo and Hausmann (2009) developed a new methodology for the empirical analysis of the process of economic development. Instead directly measuring capabilities, their methodology infers the complexity of a country's productive structure based on information on the goods countries export with revealed comparative advantage (RCA - Balassa, 1965). In other words, the approach assumes that countries that have RCA in the production/trade of a particular product possess the capabilities required for the competitive production of this product. Consequently, observing the number of products a country produces with RCA (diversification) and the number of countries capable of producing each good with RCA (ubiquity) makes it possible to establish the levels of complexity of each product and country. Thus, in accordance with the structuralist approach, in Hidalgo and Hausmann's (2009) framework, each country's economic development is determined by its ability to accumulate the capabilities required to produce more sophisticated products.

The methodology's potential to evaluate growth divergence as well as development paths was made clear by Felipe et al. (2012), who shows the measures of economic complexity correlate with measures of technological capabilities used in Schumpeterian works.

In this vein, this paper extends the approach developed by Hidalgo et al. (2007), Hidalgo and Hausmann (2009) and Hausmann et al. (2007) to analyse the relationship between structural change and economic complexity for Brazil and South Korea. The paper explores two main arguments. First, given the relationship between economic complexity and GDP per capita established in the literature, the product space network must reflect the international division of labour as well as global trade patterns through time. Secondly, we show that two very distinct paths of development can arise from an increasing export share of sophisticated manufactures, at the one hand, and an increasing share of sophisticated of imports, on the other. To do so, the paper constructs product space networks for each decade since the 1960's and analyses revealed comparative (dis)advantages indicators for Brazil and South Korea from the 1960s to 2000s.

Although Brazil and South Korea are very different countries in terms of culture, history, area and population size, they shared a similar path of per capita GPD until 1981 (Figure 1 below). In the 1960s Brazil's per capita GDP was actually higher than that of South Korea, and this difference persisted until mid1970s. By the end on the 1970s, however, this difference had already vanished, and while Brazil started a path of stagnation, South Korea kept the pace of growth, achieving a level of GDP per capita compatible with that of developed countries by 2010.

Figure 1 - Per capita GDPs of Brazil and South Korea 


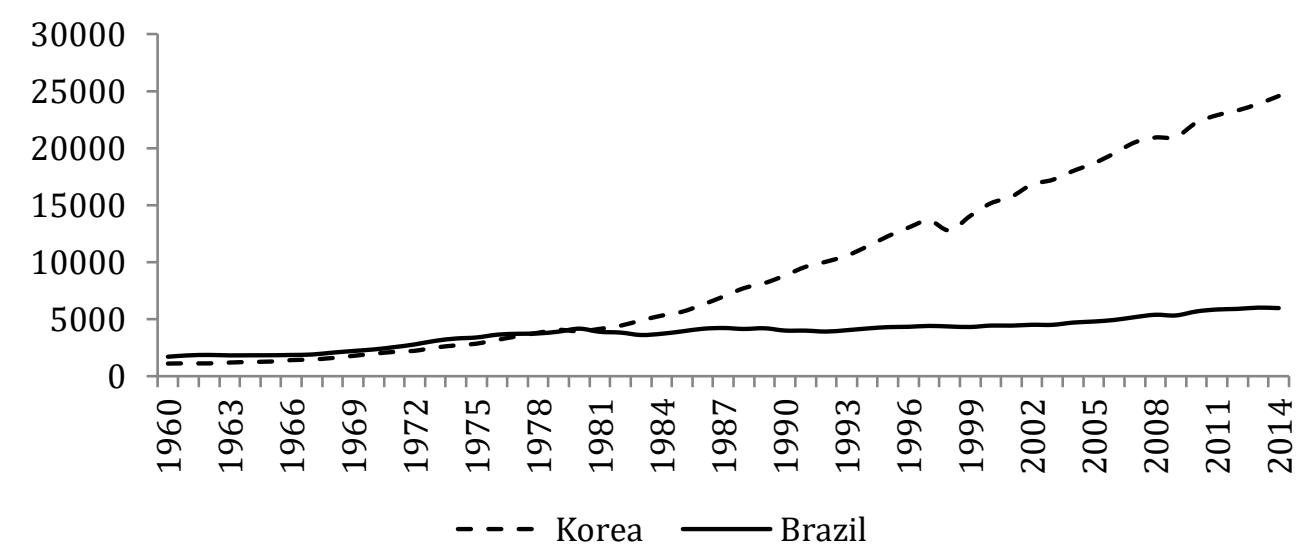

Note: Figures in constant 2005 USD.

Source: World Development Indicators.

This paper's contribution to the existing literature is threefold. First, the paper uses trade data to construct product networks for each decade in order to analyse how the structure of production and trade changes through time. Following Hidalgo et al. (2007), the linkages between goods in the product spaces were constructed based on the conditional probabilities of exporting different pairs of goods. Second, the paper proposes to use an index of revealed comparative disadvantage (RCD) based on import data to analyse the competitiveness of the domestic production in the local market. Intuitively, a decrease in the number of industries with RCD indicates an increase in the competitiveness of the domestic production in the local market. Third, the paper presents an empirical investigation of the determinants of the development trajectories of Brazil and South Korea, which provides new insights about why the movements in the GDP per capita of the two countries have been so different after the 1980s.

The remainder of the paper is organized as follows. Section 2 discusses the theoretical framework and shows the evolution of the product space from 1965 to 2005. Section 3 discusses the evolution of the productive structures of Brazil and South Korea. Section 4 brings concluding remarks.

\section{Product and economic complexity}

\subsection{Revealed comparative advantage, diversification and ubiquity}

Seeking to investigate the importance of the composition of a country's production for economic growth, Hausmann et al. (2007) proposed two measures of product and economic complexity.

The product complexity index, called PRODY, is represented by the income level associated with each product, and is calculated as the weighed average of the income per capita of the countries that export the given product. Formally:

$\operatorname{PRODY}_{k}=\sum_{j}\left[\frac{\left(x_{j k} / \sum_{k} x_{j k}\right)}{\sum_{j}\left(x_{j k} / \sum_{k} x_{j k}\right)}\right] Y_{j}$

where $x$ denotes the exports of good $k$ by country $j$, and $Y$ is income per capita. According to Hausmann $e t a l$. (2007: 10), however, this weight captures the relative specialisation of the country in a given product.

The PRODY index, therefore, ranks the commodities "according to the income levels of the countries that export them" (Hausmann et al., 2007: 9). ${ }^{1}$ This index, therefore, does not capture differences in product complexity between countries, and is an outcome-based measure of complexity that is based on the assumption that if a given product is largely produced by rich countries, then the product is regarded as "sophisticated".

The economic (or country) complexity index, called EXPY, in turn, represents the productivity level associated with a county's export profile, and is calculated as the weighted average of the complexity of the products exported by the country. Formally:

\footnotetext{
${ }^{1}$ To obtain a single ranking, the authors take the average of the PRODY over the years analysed.
} 
$E X P Y_{j t}=\sum_{k}\left(\frac{x_{j k t}}{\sum_{k} x_{j k t}}\right) P R O D Y_{k}$

where the weights are the value shares of each product in the country's total exports (Haumann et al., 2007: 10).

Using this approach, Hausmann et al. (2007) showed that current export complexity is a good predictor of future economic growth. In other words, this approach suggests that fast growing countries have EXPY indexes higher than their actual per capita incomes (such as China and India), which indicates they are producing goods associated with higher income levels (Hausmann et al., 2007: 3).

Nonetheless, although Hausmann et al. (2007) show that producing sophisticated goods leads to high growth rates, the authors' investigation provided only an initial approximation to the determinants of EXPY. Hausmann et al. (2007) argue that entrepreneurship and cost discovery drive structural transformations towards the production of highly sophisticated goods. Still, their empirical investigation only indicates that $E X P Y$ is positive correlated with population size and land area, and not correlated with human capital and institution quality (measured by rule of law).

Hidalgo et al. (2007) addressed this limitation by investigating whether the productive structure of a country influences the path, the costs and the speed of change towards the production of sophisticated goods. As the authors stress, the production of different types of goods requires different capabilities. Consequently, a country's capabilities determine the goods it can produce and how difficult it is for the country to start producing goods that require different (or additional) capabilities. Conversely, the range of goods a country can produce and the complexity of these goods indicates the capabilities a country possesses.

Thus, to identify the efficiency of each economy in producing each product, Hidalgo et al. (2007) used the index of revealed comparative advantage (RCA) developed by Balassa (1965):

$$
R C A_{j k t}=\left(\frac{x_{j k t} / \sum_{k} x_{j k t}}{\sum_{j} x_{j k t} / \sum_{j} \sum_{k} x_{j k t}}\right)
$$

The index of RCA developed by Balassa (1965) has a straightforward interpretation. If the index is higher than one, then the country has high competitiveness in the production of the given good. The opposite hols if the index is lower than one.

Hidalgo et al. (2007) then proposed to use conditional probabilities to establish how close products are in terms of the capabilities required for their production. This approach is based on the assumption that the probability of producing two products that require similar capabilities is higher than the probability of producing two goods that require different capabilities. Thus, Hidalgo et al. (2007: 484) used trade data from UN Comtrade, which is available at a highly disaggregated level for a high number of countries and years, to calculate the probability of a country exporting product $i$ with RCA given that it exports product $k$ with RCA. The authors called proximity this conditional probability. Finally, adopting a threshold value for proximity, the authors established linkages between products, creating a network that they called product space. An update version of the product space network is presented in Figure 2.

Using product space, Hidalgo et al. (2007) showed that less developed countries tend to produce goods with low number of linkages, which makes it difficult for these countries to diversify their productive structure and move towards the production of more sophisticated goods. The opposite holds true for developed countries. Thus, the authors reach three conclusions: (i) different countries face different opportunities for increasing their economic growth, given their distinct productive structures and associated capabilities; (ii) structural change and economic growth are highly path dependent, given that each country's initial productive structure reflects a different set of capabilities and these capabilities determine the possible trajectories of structural change; and (iii) moving towards sophisticated goods takes time, since this process requires leaning new capabilities and less sophisticated goods are not associated with many other activities (Hidalgo et al., 2007: 487). ${ }^{2}$

\footnotetext{
${ }^{2}$ Hidalgo et al. (2007: 487) simulated how the position of a country evolves when allowed to repeatedly move to products with proximities greater than a given value. The simulation revealed that only after 20 iterations, in general, poor countries could reach high-productivity areas of the product space.
} 


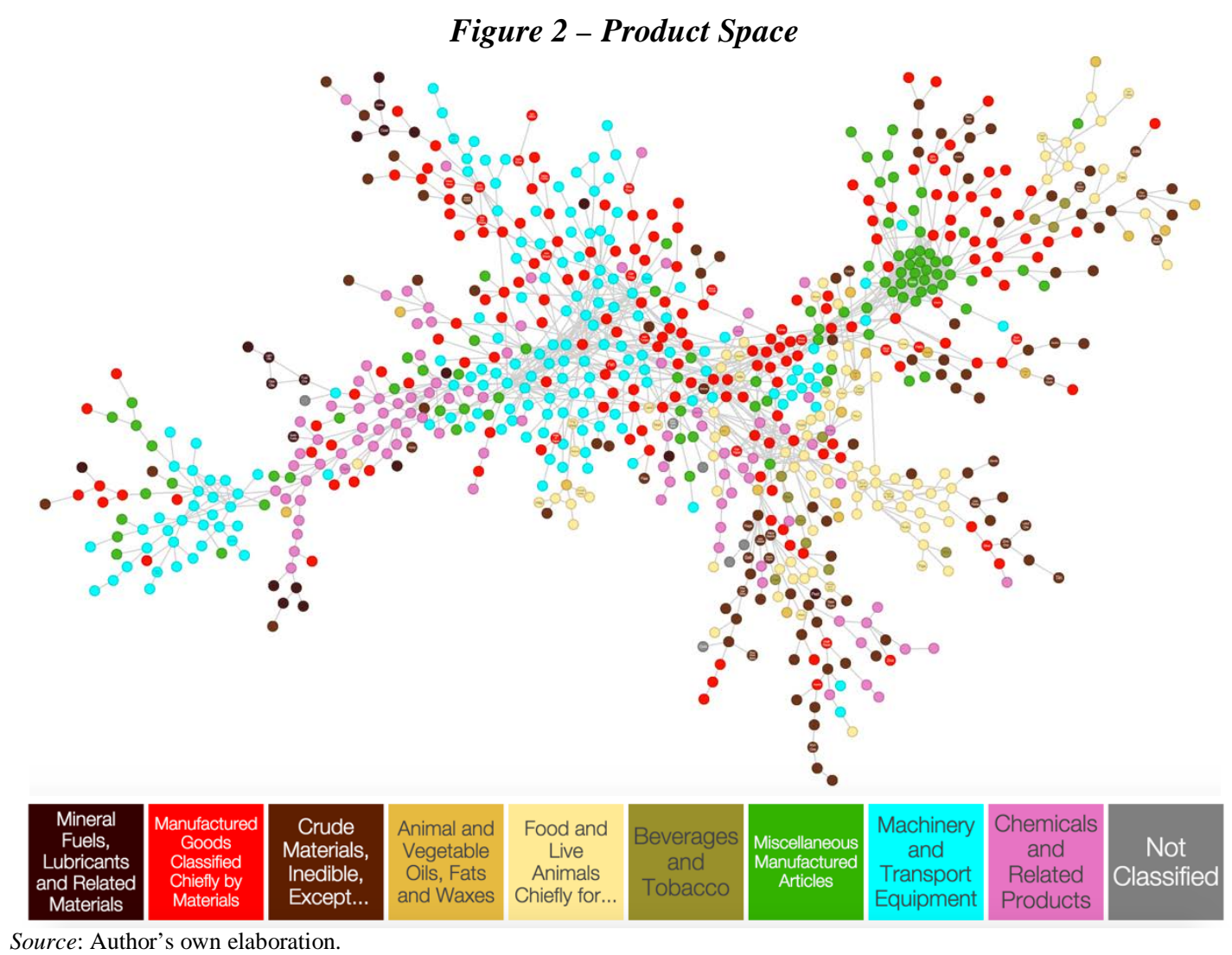

Another limitation of the measures proposed by Hausmann et al. (2007) is that the indicators do not explain what makes the products exported by rich countries important for economic growth. Indeed, the $P R O D Y$ index is simply based on the assumption that sophisticated (high-productivity) goods are the goods exported by high-income countries. As Felipe (2012: 38) stresses, this makes the approach circular. Moreover, this creates some counter-intuitively high measures of product complexity. To illustrate this problem, Reis and Farole (2012: 50) point out that the PRODY of bacon and ham is higher than the PRODY of internal combustion engines.

Hidalgo and Hausmann (2009) address this limitation by developing alternative measures of product and economic complexity. The authors defined the degree of product diversification of a country as the number of products that a country exports with RCA, and the degree of ubiquity of a product as the number of countries that export a product with RCA. Formally:

$$
\begin{aligned}
& D_{j t}=\sum_{k} N_{j k t} \\
& U_{k t}=\sum_{j} N_{j k t}
\end{aligned}
$$

where $D$ denotes diversification, $U$ denotes ubiquity and $N=1$ if country $j$ exports product $k$ with RCA at time $t$, and $N=0$ otherwise. Thus, the higher the diversification of a country's exports is, the higher this country's complexity is. In contrast, the lower the ubiquity of a good is, the higher its complexity is.

Using these indexes, Hidalgo and Hausmann (2009) and Felipe (2012) showed that economic growth is strongly correlated with the production of a diversified basked of goods that are not exported by many other countries. As Hidalgo and Hausmann (2009) argue, complex products are less ubiquitous. Furthermore, countries that possess a high number of capabilities are capable of producing a higher number of goods, which means they will tend to have more diversified productive structures. Indeed, Felipe (2012) finds that the measures of economic and product complexity proposed by Hidalgo and Hausmann (2009) are highly correlated with measures of technological capabilities used in Schumpeterian works (e.g. Archibugi and Coco, 2005). Consequently, this approach shows that not only diversification and ubiquity are negatively correlated, which means diversified countries tend to produce more complex (less ubiquitous) goods, but diversification is positively correlated with income level. 
However, as Hidalgo and Hausmann (2009) and Hausmann et al. (2011) stress, diversification and ubiquity are crude approximations of economic (or country) and product complexity. On the one hand, the ubiquity of a product can be low because of its rarity, as is the case of diamonds, and not because of its complexity. On the other hand, a country can have low diversification, but produce highly complex products.

Nonetheless, ubiquity and diversity can be combined to obtain better measures of economic and product complexity. A country with low diversification but that produces goods with high ubiquity can be considered more sophisticated than a country that has similarly low diversification but produces goods will low ubiquity. Analogously, a good with high ubiquity but produced by countries that have low diversification can be considered less sophisticated than goods with similarly high ubiquity but produced by countries that have high diversification. ${ }^{3}$ In other words, average ubiquity and average diversification are better proxies for economic and product complexity, respectively. Formally:

$$
\begin{aligned}
& P S_{k t}=\left(\frac{1}{U_{k}}\right) \sum_{j} N_{j k t} D_{j t} \\
& E S_{j t}=\left(\frac{1}{\sum_{k} N_{j k t} U_{k t}}\right) D_{j t}
\end{aligned}
$$

where $E S$ and $P S$ stand for economic and product sophistication, respectively. ${ }^{4}$

The measures developed by Hausmann et al. (2007) and Hidalgo and Hausmann (2009) have been employed by a number of works to analyse the development trajectories of different countries, taking into account the transformations in their productive structures. Felipe et al. (2010), for instance, has shown that Pakistan was not able to move towards the production of more sophisticated goods, which resulted in recurrent balance-of-payments problems, curtailing the country's growth. Felipe et al. (2013), in turn, showed that the successful development trajectory of China was associated with progressive increases in the RCA of products with high complexity (especially machinery and electronics).

In addition, recent works have been extrapolating these measures and using them in econometric investigations. Bochma et al. (2013), for example, applied the approach to the analysis of technological proximity and technological change in US cities. Using patent data from the United States Patent and Trademark Office (USPTO) disaggregated by International Product Categories (IPC), the authors calculated an index of Revealed Technological Advantages (RTA) analogous to Balassa's (1965) RCA and used it to construct a technology space analogous to Hidalgo's et al. (2007) product space. Using the technological proximity between different patent classes, the authors showed that different technological capabilities influence different trajectories of technological specialization between cities. Bahar et al. (2014), in turn, used RCAs and an export similarity index to show that geographic proximity influences the productive specialization of neighbouring countries. In other words, countries that are geographically close tend to present RCAs in similar products. The authors attribute this result to technological diffusion.

\subsection{Revealed comparative disadvantage, bottlenecks and potential industries}

This section presents the first set of contributions of this paper, which consists of proposing indexes that complement the information provided by the indexes discussed in the previous section.

Using data on imports, it is possible to calculate indexes of revealed comparative disadvantage (RCD) analogous to the index of RCA. Formally:

$$
R C D_{j k t}=\left(\frac{m_{j k t} / \sum_{k} m_{j k t}}{\sum_{j} m_{j k t} / \sum_{j} \sum_{k} m_{j k t}}\right)
$$

\footnotetext{
${ }^{3}$ As Hausmann et al. (2011: 20) stress, this process can be repeated to progressively increase the information captured by the measures, which will converge after a few iterations.

${ }^{4}$ It is important to note that ES is the inverse of the measure proposed by Hidalgo and Hausmann (2009). This makes its interpretation more straightforward: the highest $E C$ is, the highest the complexity of the country is. This stems from the fact that the highest the ubiquity of a product, the less unique it is, and the less sophisticated are the countries that produce it (Felipe et al., 2013: 803).
} 
where $m$ denotes imports.

This measure captures the competitiveness of the domestic production in the local markets. If $R C D>1$, the country is an effective importer of good $k$, while if $R C D<1$, the country is not an effective importer, which means its competitive disadvantage is not too large. The most interesting case is the later, which indicates that although the country has no RCA in the production of a given good $k$, the domestic production is still capable of competing with imports. This situation is similar to the case of non-traded goods described in international trade theory. As Dornbusch et al. (1977) have shown, in theory, a country might produce goods in which it has a comparative disadvantage if transportation costs or tariffs are large enough to compensate for the advantage that the foreign competitors possess. Still, it is also possible that domestic production is so weak that there are no imports of some intermediate products, or that the level of income of the domestic economic does not generate enough demand for some particular products.

Thus, analogously to the index of export diversification $D$, it is possible to develop indexes to indicate the size of the bottlenecks $(B)$ of the domestic productive structure, the number of industries where intra-industry $(I)$ trade occurs (i.e. industries with both RCA and RCD), and the number of industries with potential $(P)$ to become competitive exporters (i.e. the industries in which domestic production has no RCA, nor RCD), namely:

$$
\begin{aligned}
& B_{j t}=\sum_{k} M_{j k t} \\
& I_{j t}=\sum_{k}^{k} N_{j k t} M_{j k t} \\
& P_{j t}=T+I_{j t}-\sum_{k}\left(N_{j k t}+M_{j k t}\right)
\end{aligned}
$$

where $M=1$ if country $j$ imports product $k$ with RCD at time $t$, and $M=0$ otherwise. Moreover, $T$ is the total number of industries,

Using these indexes it is possible to identify how the domestic production is performing in the local market. Hence, this analysis complements and extends the approach proposed by Hidalgo's et al. (2007) and Hidalgo and Hausmann (2009). Most importantly, these indexes make it possible to observe how the industries without RCA are performing, indicating if they are becoming industries with a potential to export, or if they are loosing competitiveness and becoming industries with RCD.

It is important to note, however, that the index $P$ provides only an indication of the industries that might have some potential to become exporters. Although this index assumes that an industry without RCD has a relative level of competitiveness in the domestic market, another scenario is possible: the industry might not have RCD because imports are low due to the lack of demand for this product at home, especially when considering intermediate inputs that are not used in the local production, or when the domestic demand for a final product is low because of different preferences or income levels. Analogously, an industry might not have RCA because domestic production exists but its not competitive enough, but it is also possible that an industry has no RCA because there is no domestic production of this product at all. Thus, these important caveats must be kept in mind when analysing the number of potential industries.

\section{Brazil and South Korea's development trajectory}

\subsection{Data description}

To analyse the development of the productive structures of Brazil and South Korea between 1962 and 2010 using the methodology described in the previous section, trade data classified according to the Standard International Trade Classification (Revisions 1 and 2) 4-digits was gathered from the UN Comtrade. This classification encompasses 613 products in revision 1, and 784 products in revision 2. The two versions are used in this work due to fact that revision 1 is the only one available from 1962 to 1973. These industries were divided in 6 technological sectors, following the classification proposed by Lall (2000): (i) Primary Products, with 135 industries in revision 1 and 148 industries in revision 2; (ii) ResourceBased Manufactures, with 187 industries in revision 1 and 197 industries in revision 2; (iii) Low-Tech Manufactures, with 128 industries in revision 1 and 161 industries in revision 2; (iv) Medium-Tech Manufactures, with 113 industries in revision 1 and 202 industries in revision 2; (v) High-Tech Manufactures, with 38 industries in revision 1 and 66 industries in revision 2; and (vi) Other Manufactures, with 12 industries in revision 1 and 10 industries in revision 2. Whenever possible, revision 2 is utilized, 
although in some cases it is necessary to use revision 1 to make comparisons throughout the whole period possible.

Table 1 - Average index of product complexity (PC) by technological sector

\begin{tabular}{cccccc}
\hline \hline $\begin{array}{c}\text { Primary } \\
\text { Products }\end{array}$ & $\begin{array}{c}\text { Resource- } \\
\text { Based }\end{array}$ & Low-Tech & Medium-Tech & High-Tech & $\begin{array}{c}\text { Other } \\
\text { Manufactures }\end{array}$ \\
\hline-0.711 & -0.230 & 0.205 & 0.714 & 0.806 & 0.120 \\
\hline \hline Source: Authors' elaboration.
\end{tabular}

Table 1 above shows the average product complexity (PC) of each technological sector. This table indicates how there is a clear correlation between the technological content of each industry and the level of complexity of its production. Consequently, this table justifies the focus of this paper on the division of industries according to Lall's (2000) technological classification, since a process of structural change towards high-tech industries can be also interpreted as a process of increase in the complexity of the country's productive structure.

\subsection{Changes in product space through time}

To understand how the structures of world production and trade have changed through time, a product space was constructed for each decade. Changes in this network are associated with the evolution of international division of labour, which are reflected in the transformations in patterns of international trade. The evolving structure of the product space, which represents the second contribution of the paper, is shown in Figure 3 below. The upper part of the figure shows the long-term change of the product space from 1965 to 2005. The lower part of the figure shows the progressive, decennial changes occurred in between, in 1975, 1985 and 1995, respectively.

The shape of the network for 2005, as can be readily seen, is exactly the same as Hidalgo et al. (2011) presented in Figure 2 above. However, in this case products are classified using the technological classification of products developed Lall (2000), instead of Laemer's (1984) classification used by Hidalgo et al. (2007). This classification should provide more information about the characteristics of simple and sophisticated products.

Similarly to the original product space, there is a clear-cut segmentation of the product space. Highand medium-tech goods are positioned to the centre-left of the figure. In this region a clear blue stripe can be seen. It corresponds to electronic and chemical goods. On the other hand, low-tech, resource-based and primary goods are generally located to the centre-right of the figure, with the latter also poisoned in the fringes of the product space. A distinct node of low-tech (garments) goods is visible, surrounded by other low-tech and primary goods. The product space for 1965 is considerably more concentrated around a large central node, formed mostly of high, middle and low-tech goods. A more disperse ring of the same type of goods appears around the central node, with low-tech goods spilling over to the lower left. On the other hand, resource-based and primary goods are plotted in the fringes, particularly in the upper-left side of the network. This structure is consistent with marked division of labour and trade between primary and manufactured goods. In addition, this radial geography of the product space in terms of technological intensity is suggestive of a centripetal path of development through successive waves of industrial upgrade from primary based production towards higher-tech, more complex goods in the middle.

All networks were constructed using the Maximum Spanning Tree method, which, amongst other things requires selecting a threshold for the proximity between nodes in other to allow for a meaningful visualisation of the links between nodes. From 1965 to 2005, this threshold decreases markedly. To plot the network in 1965 a threshold of 0.70 was necessary. For 1975 and 1985, however, the proximity adopted was 0.65 , and for 1995 the proximity was 0.55 , as for 2005. These calibration changes carry information regarding international trade patterns as well as country specialisation. This figures show that the probability of co-exporting a number of goods was very much higher in the 1960s, which indicates that international trade was more concentrated in terms of value and more segmented in terms of sectors.

With time, the diversity of exported goods increases, as does the participation of less developing industrializing countries in international trade. Parallel advances in the internationalisation of production, with the proliferation of multinational corporations, also contribute to the increase of intra-industry and intrasectoral trade. On the other hand, product differentiation and complexity increases consistently, stemming from ever growing technological efforts in more advanced countries. As expected, the product space changes 
accordingly. The shapes of the networks in the lower part of Figure 3 show this dynamic. The network becomes more elongated, and the distinction of goods using the technological intensity increases steadily to form the familiar shape in 2005. The notional development path becomes a long U-shaped curve, as complex and more simple products become further and further apart reflecting a very distinct international division of labour and very low probabilities of co-exportation of such distinct products.

The changing shape of the network is instrumental in showing the importance of considering products in terms of technological intensity in addition to more traditional resource based classifications. As it is clear in Figure 3, there is a growing segmentation of exports in terms of technological intensity within the networks from 1965 to 2005 with a line leading from low-tech, in the right hand side, though medium tech in the middle, to high tech in the right hand side. 


\section{5 (a)}

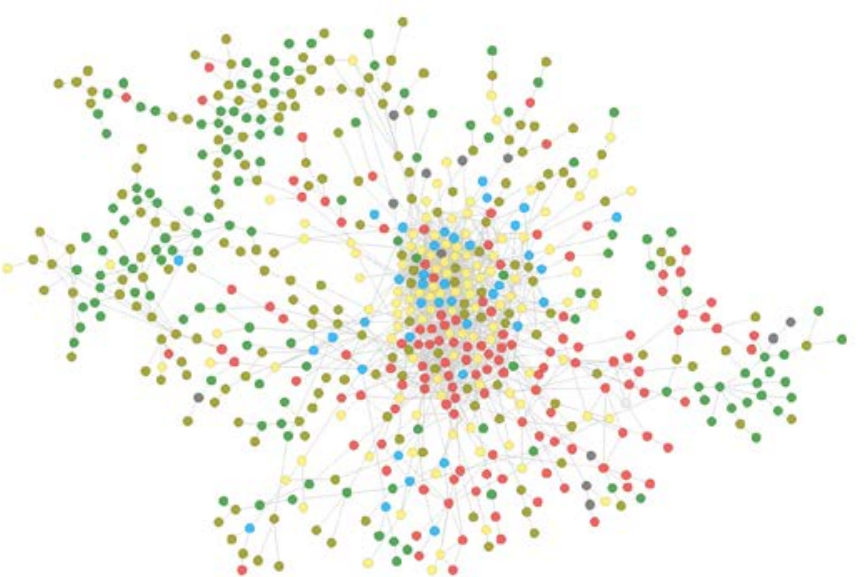

Figure 3 - Changes in product space through time

2005 (b)

1975 (c)

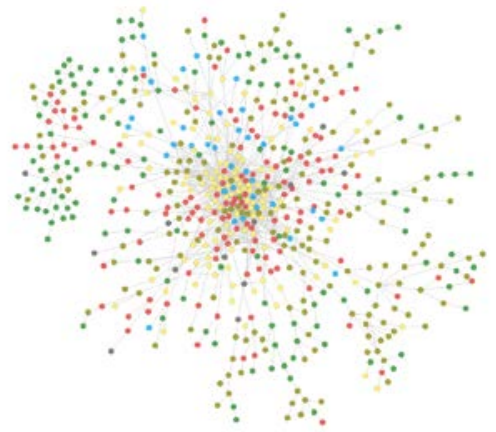

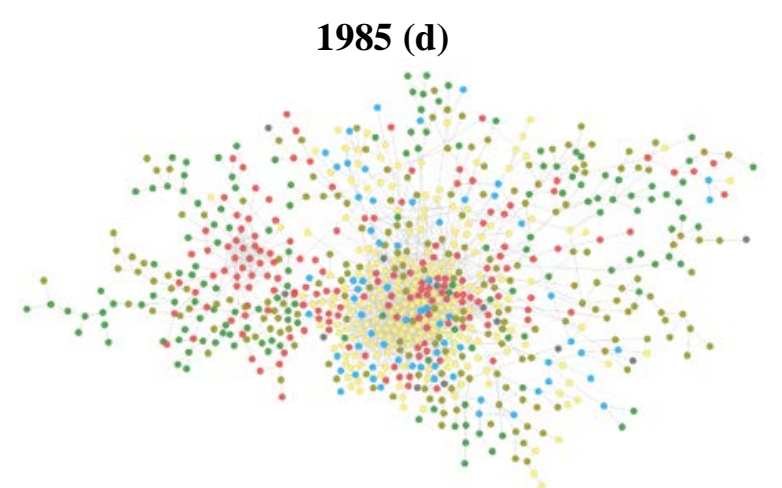

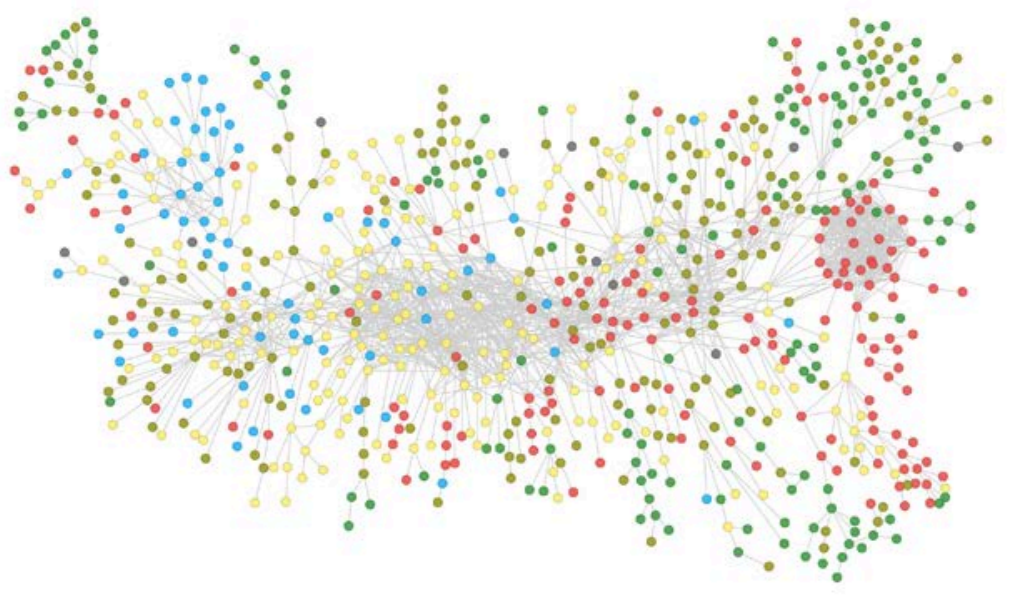

1995 (e)

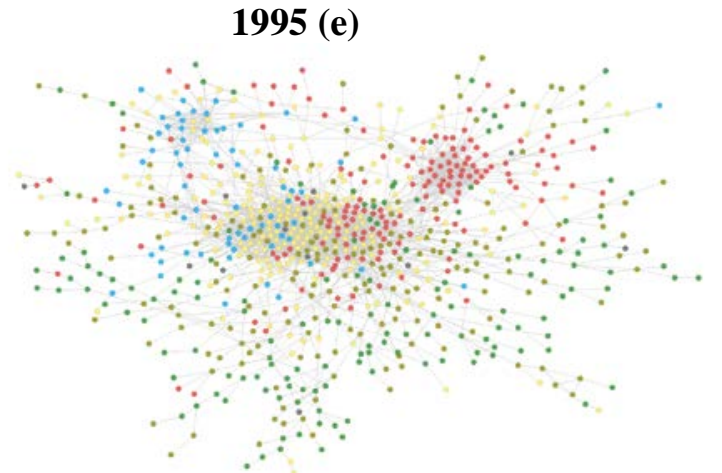

$\begin{array}{ll}\text { Low-Tech Manufactures } & \text { Primary Products } \\ \text { Medium-Tech Manufactures } & \text { High-Tech Manufactures } \\ \text { Resource-Based Manufactures } & \text { Other Manufacturing Products }\end{array}$

Note: Networks for 1965 and 1975 were calculated using SITC Rev. 1 (4-digits), and the remainder using SITC Rev. 2 (4-digits).

Source: Authors' elaboration. 


\subsection{Revealed Comparative Advantages}

Figure 4 shows the evolution of productive diversification in Brazil and South Korea, dividing the figures by technological sectors. This figure conveys four important pieces of information. First, as expected, Brazil has always been more competitive in Primary Products than South Korea, while the latter has always been more competitive in Low-Tech Manufactures than Brazil. Secondly, from 1978 onwards Brazil has focused on increasing the competitiveness of Resource-Based Manufactures, while South Korea has focused on increasing the competitiveness of Low-Tech Manufactures. Thirdly, diversification in Medium-Tech Manufactures is, in general, similar in both countries throughout the period. Finally, the number of HighTech Manufactures with RCA is considerably larger in South Korea.

Brazil had already a considerable number of Primary Products and Resource-Based Manufactures with RCA in 1960. Heavy industries started to be created and supported since the dictatorship of president Vargas, from 1930 to 1950, and automobile and communication industries were settled during the government of president Kubtschek from 1955. After the military coup that took place in Brazil in 1964, a number of reforms were implemented: (i) fiscal reform; (ii) restructuration of the financial system; (iii) reduction of the inflation rate; and (iv) adoption of industrial policies to incentivise exports. From 1964 to 1973 Brazil experience a miraculous growth of over 8\% per year, based on the strategy of industrialization via import substitution. With the first oil chocks of 1973, however, Brazil started to experience balance-ofpayment difficulties, and president Geisel chose to go ahead with the process of import substitution, incentivizing the domestic production of intermediate inputs and machinery (Burlamaqui et al., 2006: 11).

In the 1980s, after the second oil shock, Brazil's growing foreign debt forced a recessive adjustment and ended up in a default in 1986. The decade was marked by slow growth and hyperinflation. Only in 1994 the inflation was controlled. A restructuration of the financial system was implemented, and a rapid process of liberalization and privatization took place. During these two decades, however, the GDP growth rate was just over 2\% (Netto, 2005). Only after 2004 growth rates recovered, staying around 4\%, motivated by the country's economic stability, the recovery of state investment, and the policies of wage increase and income distribution that motivated the growth of the domestic market (Serrano and Summa, 2011). As Figure 3 shows, however, after the liberalization that took place from 1994 onwards, a process of "re-primaryzation" unfolded in the Brazilian economy.

Figure 4 - Trade Diversification, 1962-2010 BRAZIL (a)

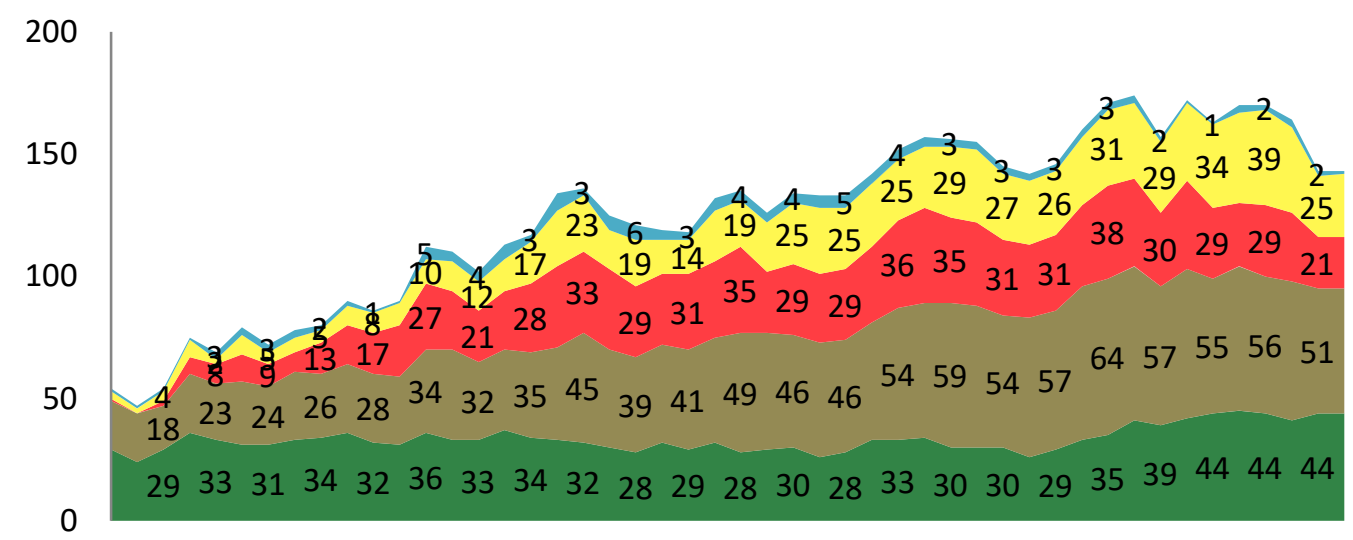

KOREA (b) 


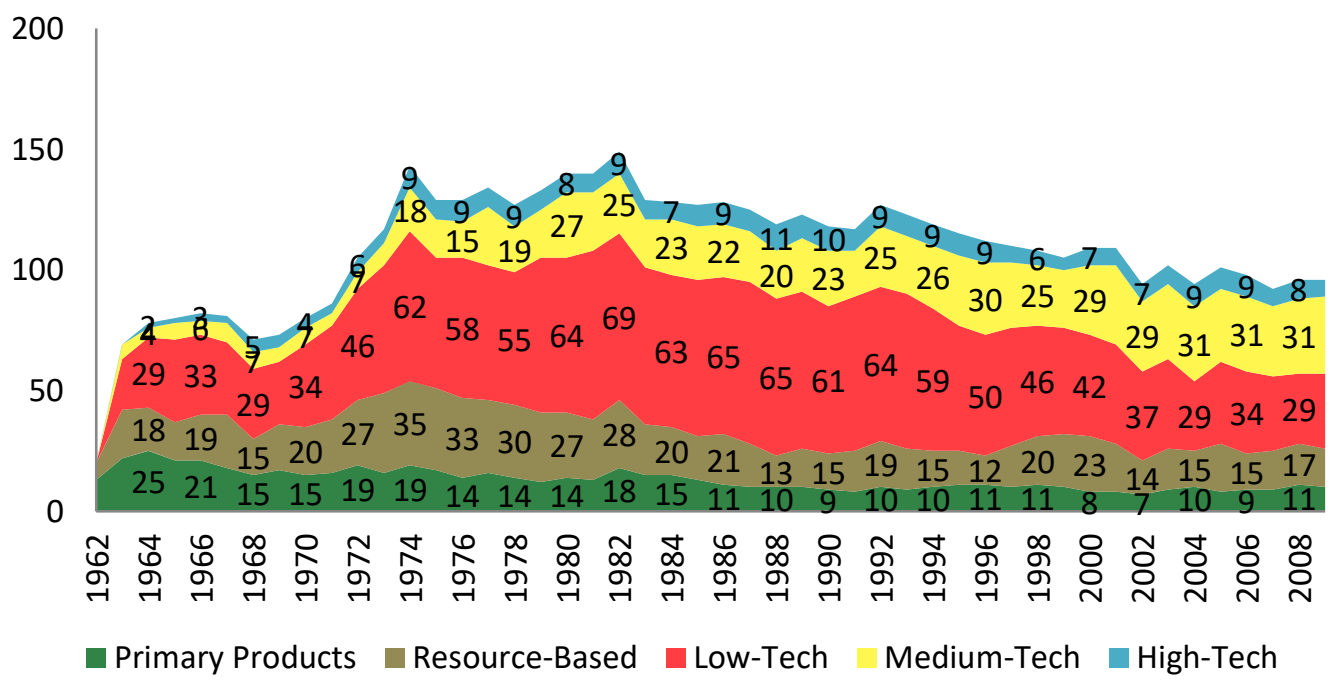

Note: SITC Revision 1 (4-digits) was used throughout the whole period.

Source: Authors' elaboration

South Korea, in contrast, had about half as many industries with RCA as Brazil in 1960. South Korea was governed by a military ruling group since 1961, led by Park Chung Hee until 1963, when Park was elected president. The period from 1963 to 1972 in South Korea is known as Third Republic and was the beginning of an industrialization effort, initially focusing on developing basic institutions to support the adoption of foreign technology. Since 1962 South Korean governments have formulated a series of five-year plans for economic growth. The objective of the first two plans was to build an industrial base, increase energy production and encourage companies to invest in acquisition of technology (see Ministry of Science, ICT and Future Planning, 2012; Kuznets, 1990; Collins, 1990). Besides the five-year plans, during president Park's term major changes were made in terms of the macroeconomic situation: (i) exchange rate reform; (ii) reduction of the inflation rate; and (iii) rise of the real interest rate, all of them were fundamental to finance the high investment rates required in a rapid growth process. A particularity of this case is that the foreign direct investment was not the main form of financing, South Korea financed industrial investments through long term foreign loans, selecting target industries for investment what stimulated the creation of chaebols, conglomerates of business very important to the productive structure of South Korea (see Zeile, 1991; Chung, 2011: 335).

During the 1960s, the chaebols were concentrated in the production of Low-Tech Manufactures, passing to the heavy Medium-Tech Manufactures and High-Tech Manufactures industries during 1970, with marked presence of the chemical, naval, automobile and machinery industries (see Jacobsson, 1993; WooCumings, 1999). This shift from light to heavy industries was planned in the third five-year plan (1972-1976) and can be seen in Figure 4. In 1960s South Korea was constructing an industrial base focusing on LowTech Manufactures. In 1970s the shift started and Medium-Tech Manufactures importance grew really fast. The number of High-Tech Manufactures industries with RCA did not suffer major alterations, but their share in exportations grew in the 1980s, signalling the concentration of the knowledge. In 1974, while the number of industries with RCA in Brazil was around 100, in South Korea this number was already around 150. In 1980, however, this gap was closed.

In the 1980s, South Korea went through a process of re-democratization that reduced the government's capacity to implement reforms and imposed the adoption of programs of structural adjustment and stabilization. Alongside with the more complex and sophisticated technological requirements of the South Korean industries and the effects of the oil shocks, this process created some difficulties for the continuity of the country's development strategy. Interestingly, democracy not only empowered worker movements, but it also generated channels for chaebols to pose its demands to the government, strengthening these groups as well (Chang, 2006, chap. 6). Hence, the 1980s were characterized by: (i) a change in the industry policy - more indirect and focused only on functional support to manufacturing; (ii) attempts to stimulate small and medium enterprises; (iii) financial liberalization; and (iv) trade liberalization with the establishment of a Tariff Reform Committee in 1983 and abolition of tariff exemptions for strategic industries in 1984 (Harvie and Lee, 2003).

Finally, in the end of the 1990s South Korea suffered with the Asian crisis, but was able to adopt reforms that led to its recovery. Financial system regulation was strengthened via the creation of the 
Financial Supervisory Commission, during Kim Dae Jung's term. This autonomous institution sought to introduce changes in corporate governance, deciding the feasibility of banks and reducing the diversification of the chaebols by eliminating the cross subsidization and concentrating the groups in the sectors they were more specialized in (Haggard, 2000, p. 142). Moreover, the reduction of the restrictions on foreign competition that started in the 1980s and was consolidated during the 1990s provided additional contribution to the process of reduction of the diversification of the chaebols and of the South Korean economy as a whole, as shown in Figure 3.

In addition, it is also important to note that the development experiences of Brazil and South Korea were also distinct due to differences in: (i) investment in education; (ii) investment in research and development (R\&D); (iii) distribution of income; and (iv) presence of an earlier industrialising country in the region - Japan was a strong partner of South Korea in 1980s, and the original equipment manufacturer (OEM) agreements made technological advances possible in a international scenario that was not favourable (Etkowitz and Brisolla, 1999).

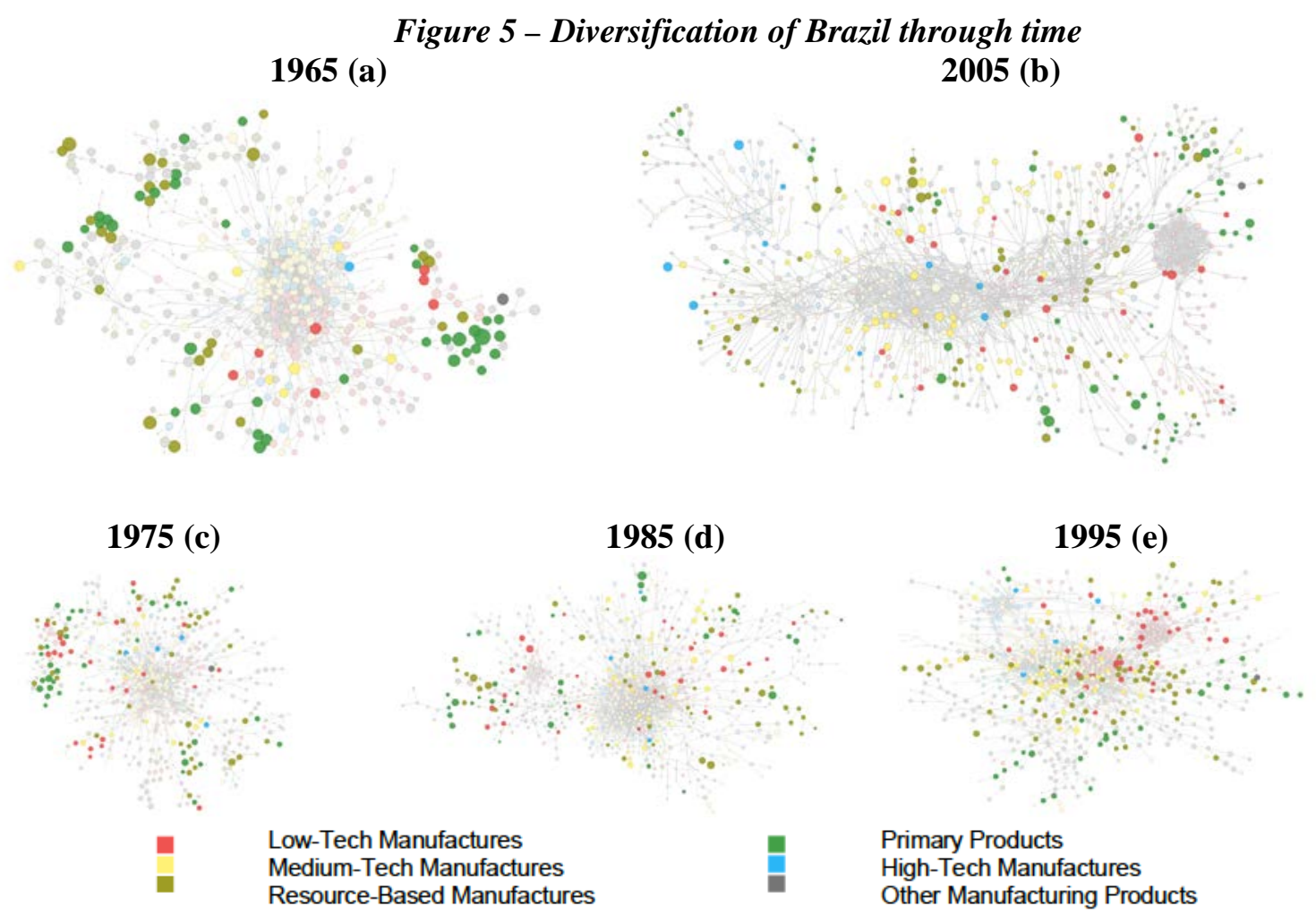

Note: Networks for 1965 and 1975 were calculated using SITC Rev. 1 (4-digits), and the remainder using SITC Rev. 2 (4-digits). Source: Authors' elaboration.

Figures 5 and 6 illustrate the evolution of the productive structures of Brazil and South Korea, respectively. The networks for 1965 indicate how the productive structure of South Korea was already more focused on low-tech products, while Brazil was still producing mostly primary products. This is a key finding, given that the comparative literature unanimously focuses on the late 1970s and early 1980s as the water divisor in terms of the economic development of the two countries.

Turning to the networks for 2005, it is noticeable that the Brazilian productive structure becomes more diversified, with a considerably larger number of industries with RCA across all sectors, but mostly resource-based and medium-tech. Yet, Brazilian exports are still marked by a considerable number of primary products with RCA. In the network of South Korea, in turn, there is an evident reduction in the number of primary and low-tech industries, with marked increases in the medium- and high-tech industries.

Confronting Figure 4 with Figure 1, however, it becomes clear that from 1980 onwards, the diversification of South Korea started to decrease, while Brazil's diversification continued to increase. Hence, apart from the superiority of South Korea in the production of Low-Tech Manufactures and HighTech Manufactures.

Figure 6 - Diversification of South Korea through time 1965 (a) 


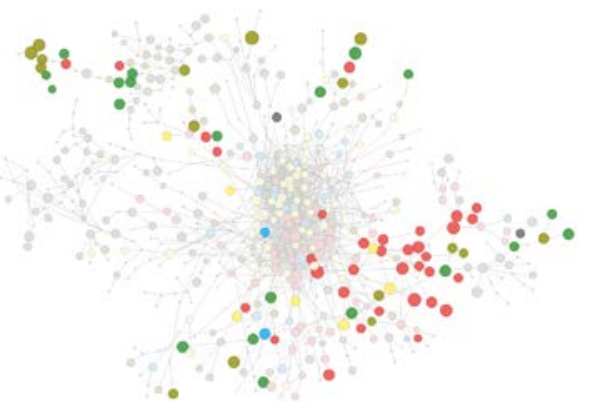

1975 (c)

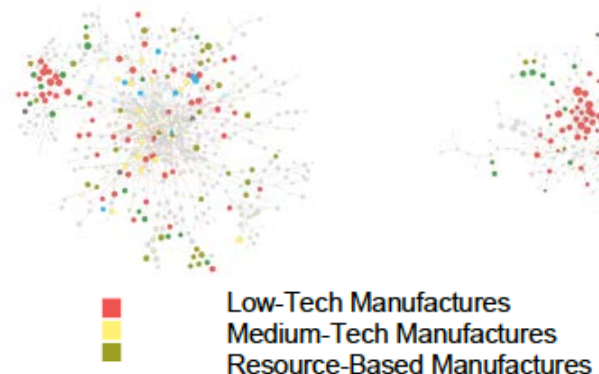

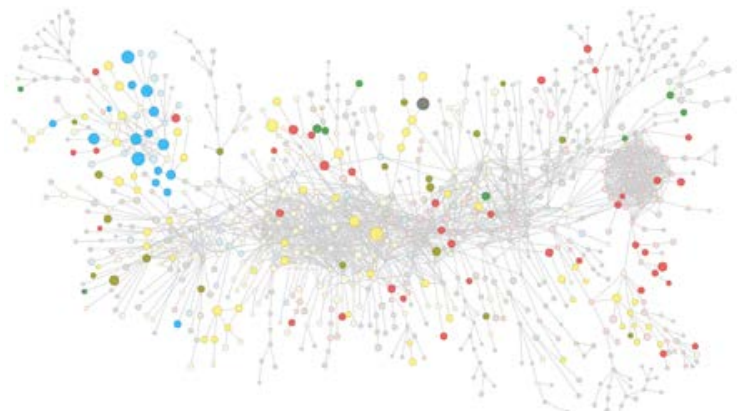

1985 (d)

1995 (e)

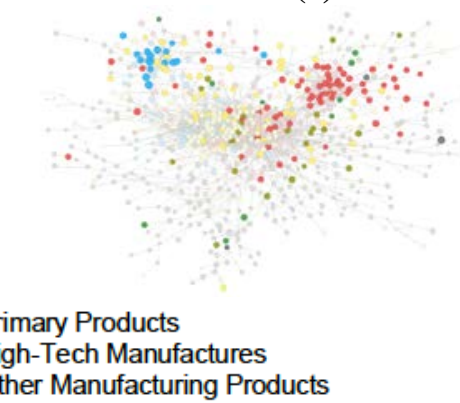

Note: Networks for 1965 and 1975 were calculated using SITC Rev. 1 (4-digits), and the remainder using SITC Rev. 2 (4-digits). Source: Authors' elaboration.

Figure 7 presents the shares of exports from each sector in the total exports of Brazil and South Korea. These figures show a striking difference between the export structure of the two countries. On the one hand, Brazil could not reduce the share of Primary Products and Resource-Based Manufactures (put together) below $50 \%$ of total exports, while Medium-Tech Manufactures and High-Tech Manufactures reached only 25 and 7\% of total exports, respectively. On the other hand, South Korea managed to reduce the share of Primary Products and Resource-Based Manufactures (put together) to 8\% of total exports, while Medium-Tech Manufactures and High-Tech Manufactures reached 44 and 29\% of total exports, respectively.

This investigation shows that the number of industries with RCA is not as important as the share of the exports in Medium-Tech Manufactures and High-Tech Manufactures. In other words, low diversification is not a problem, when the share of Medium-Tech Manufactures and High-Tech Manufactures is high enough.

Figure 7 - Export shares by technological sectors, 1962-2010 BRAZIL (a)

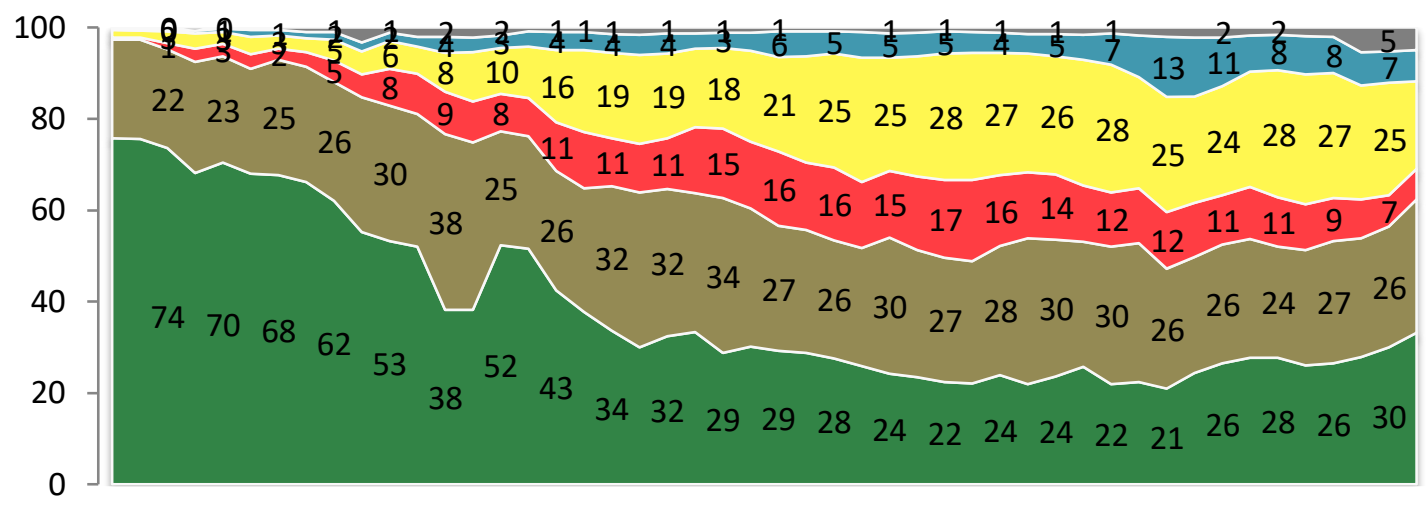

SOUTH KOREA (b) 


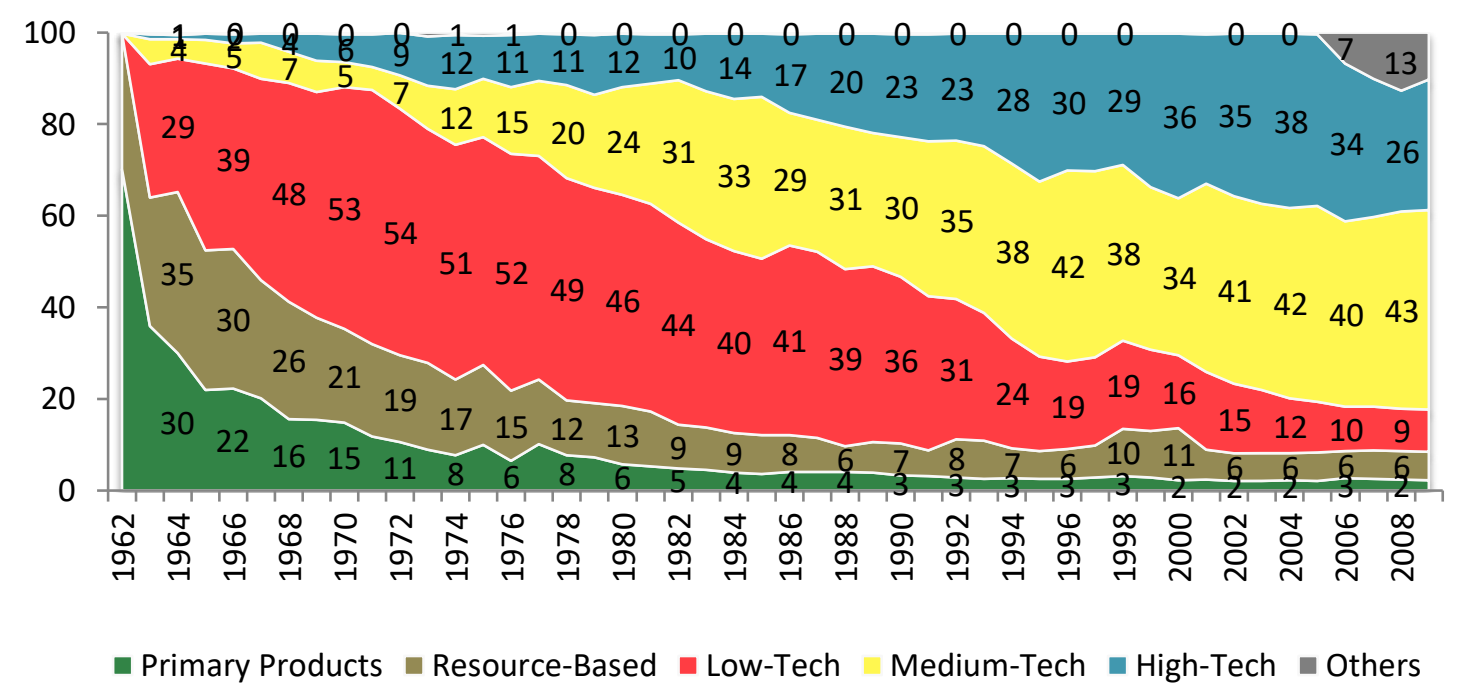

Note: SITC Revision 1 (4-digits) was used throughout the whole period. Source: Authors' elaboration.

\subsection{Revealed Comparative Disadvantages}

Figure 8 complements the analysis of the previous section, showing the evolution of bottlenecks in the productive structures of Brazil and South Korea, dividing the figures by technological sectors. This figure conveys five important pieces of information: First, Brazil has always been less competitive domestically in Medium-Tech Manufactures and High-Tech Manufactures than South Korea. Secondly, Brazil and South Korea have had considerably similar number of bottlenecks in the Primary Products and Resource-Based Manufactures. The reduction of the number of bottlenecks in Brazil during between 19801986 is a result of the external adjustment that the Brazilian economy went through, which resulted in a considerable decrease in the country's imports. There has been an increase in the number of bottlenecks in Primary Products and Resource-Based Manufactures sectors in South Korea since 1985. From 2002 onwards there has been a decrease in the bottlenecks in Primary Products in both economies.

Figure 8 - Bottlenecks by technological sector, 1962-2010 BRAZIL (a)

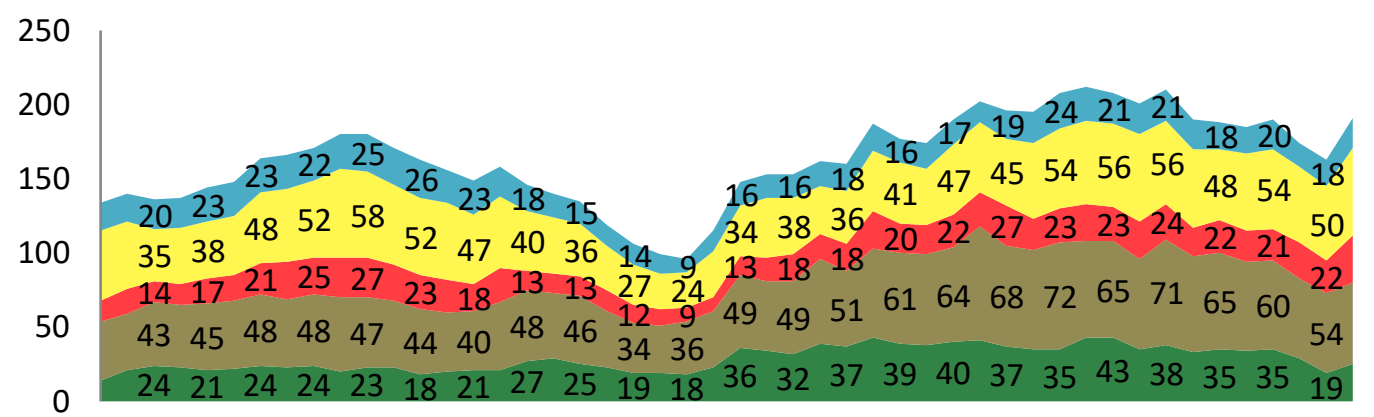

SOUTH KOREA (b) 


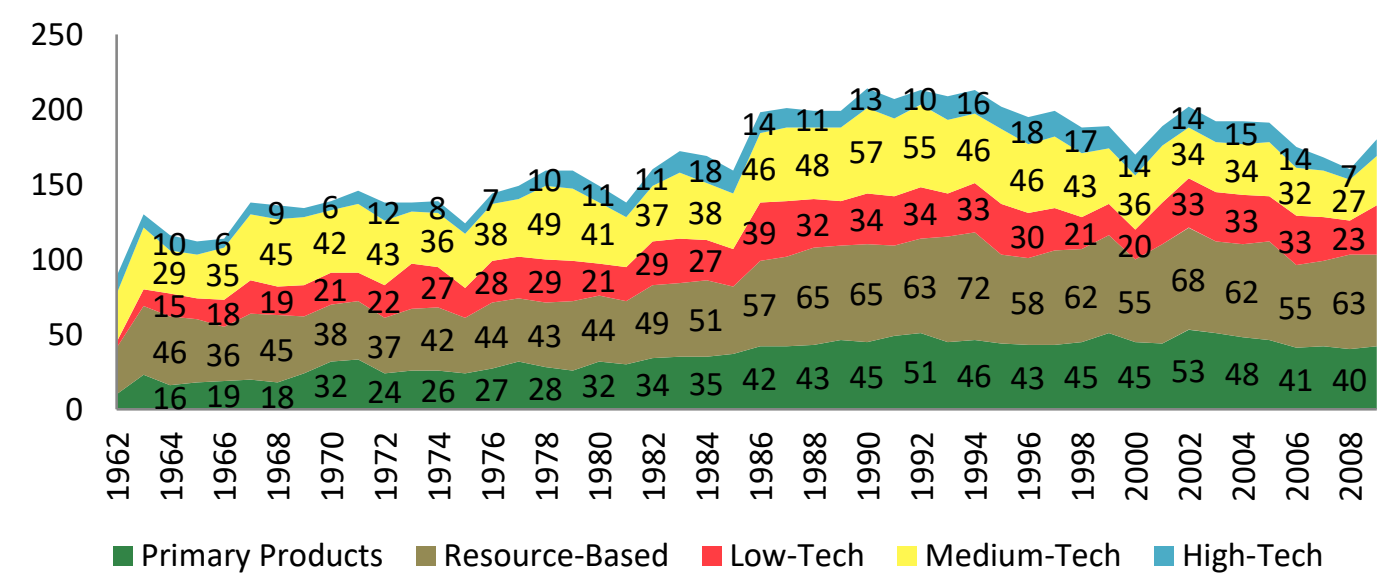

Note: SITC Revision 1 (4-digits) was used throughout the whole period.

Source: Authors' elaboration.

Figures 9 and 10 illustrate the evolution of the bottlenecks in the productive structures of Brazil and South Korea, respectively. The networks for 1965 indicate how the bottlenecks of the productive structures of Brazil and South Korea were not that different in the beginning of the period under investigation. Both countries had most bottlenecks in resource-based medium-tech industries, followed by high-tech industries. Turning to the networks for 2005, however, it is noticeable how South Korea manages to reduce the bottlenecks in medium-tech industries, in the centre part of the network, while increasing the bottlenecks in primary products, in the periphery of the product space. The Brazilian bottlenecks, in contrast, remain with a similar distribution, with a slight increase in medium-tech industries.

Figure 9 - Bottlenecks of Brazil through time

1965 (a)

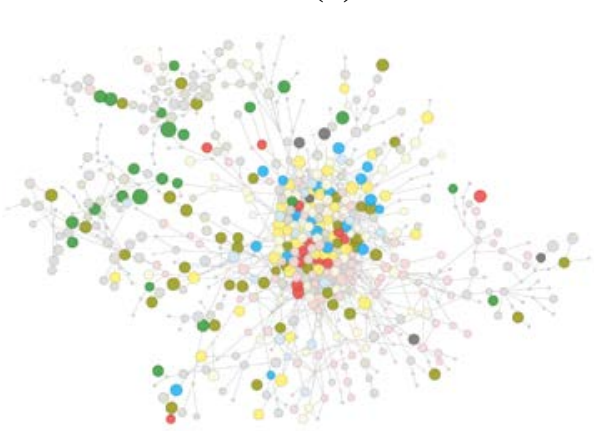

1975 (c)

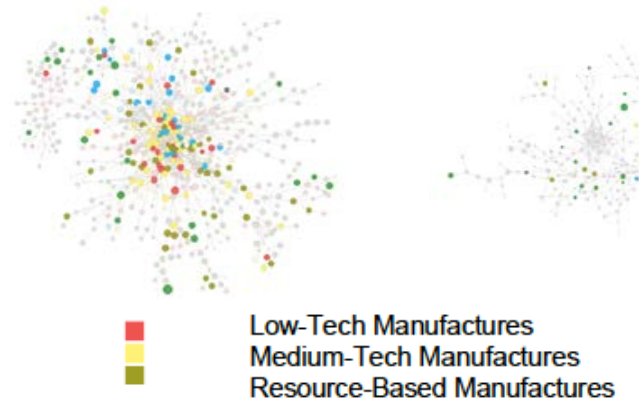

2005 (b)

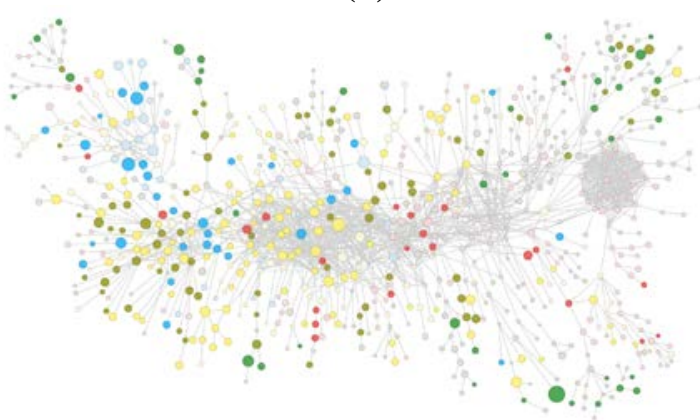

1995 (e)
1985 (d)

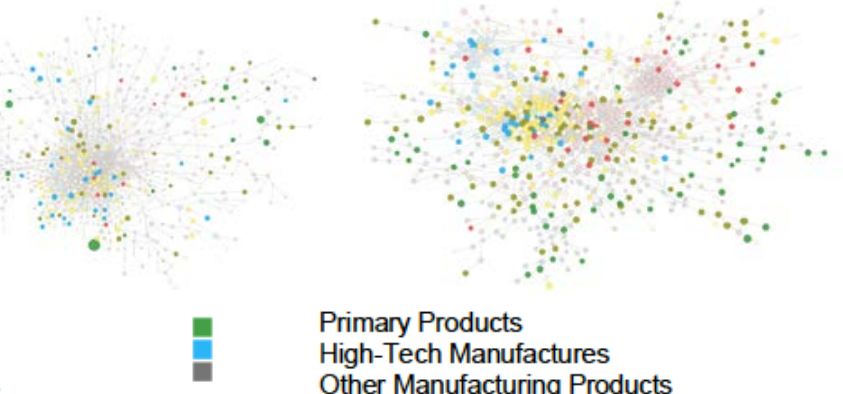

Note: Networks for 1965 and 1975 were calculated using SITC Rev. 1 (4-digits), and the remainder using SITC Rev. 2 (4-digits). Source: Authors' elaboration.

Figure 10 - Bottlenecks of South Korea through time

1965 (a)

2005 (b) 


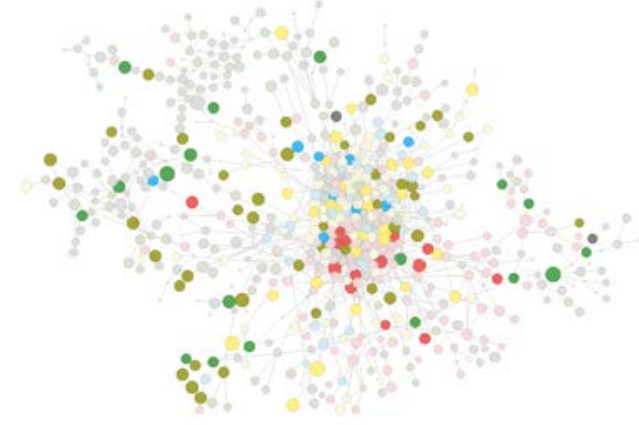

1975 (c)

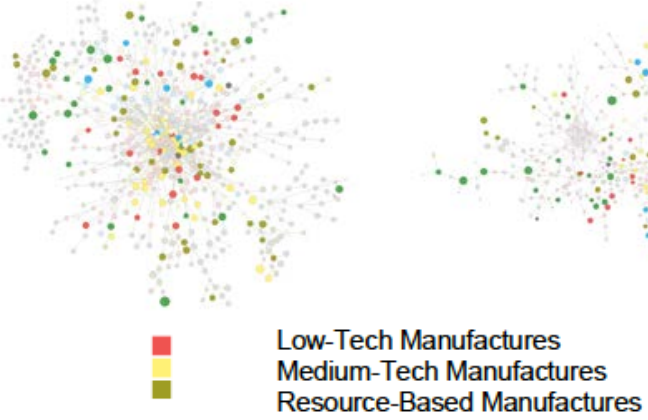

1985 (d)

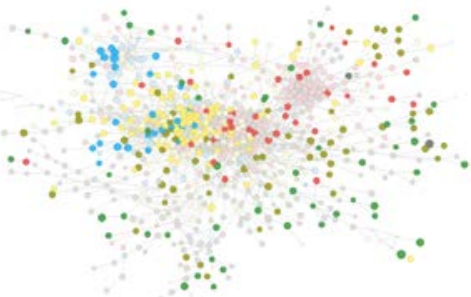

Primary Products

High-Tech Manufactures

Other Manufacturing Products

Note: Networks for 1965 and 1975 were calculated using SITC Rev. 1 (4-digits), and the remainder using SITC Rev. 2 (4-digits). Source: Authors' elaboration.

Figure 11 - Import shares by technological sectors, 1962-2010

BRAZIL (a)

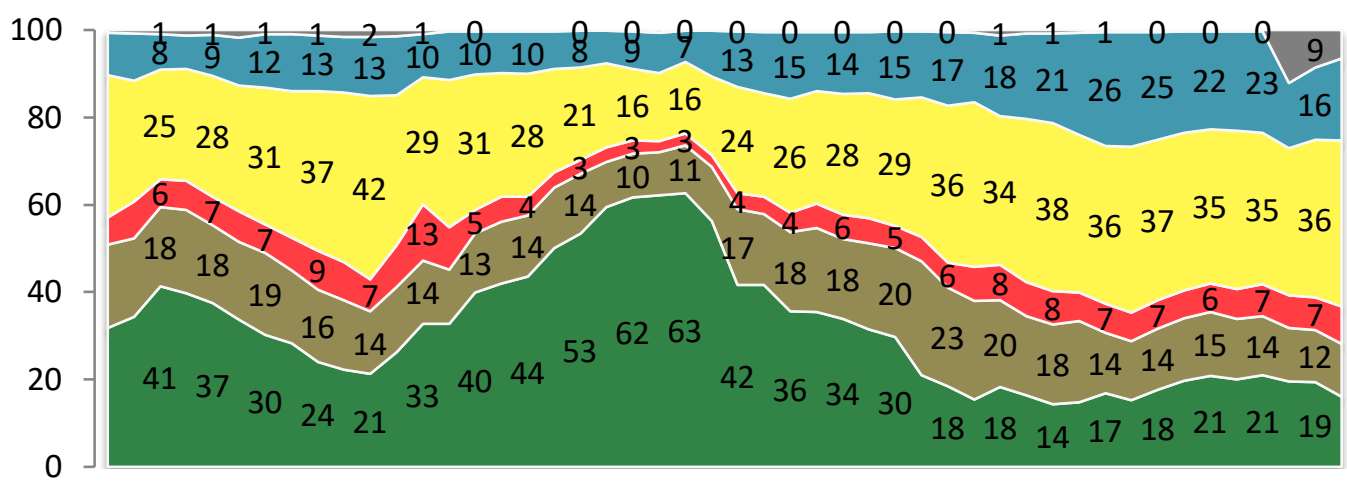

SOUTH KOREA (b)

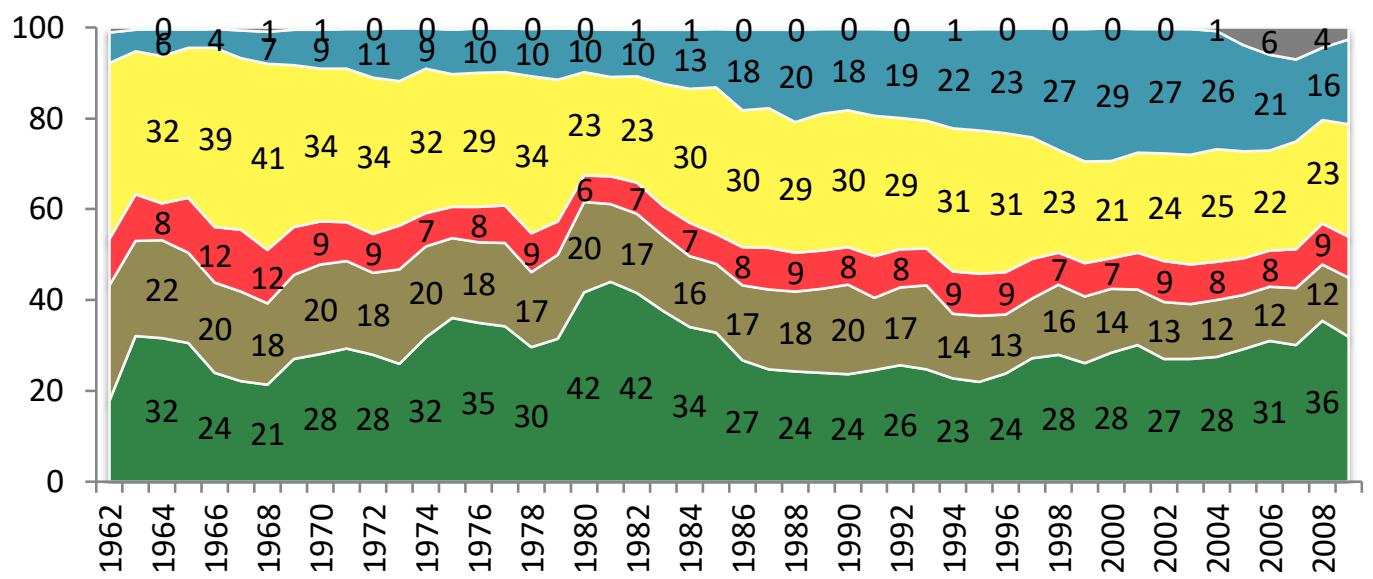

$\square$ Primary Products $\square$ Resource-Based $\square$ Low-Tech $\square$ Medium-Tech $\square$ High-Tech $\square$ Others 
Figure 11, in turn, presents the shares of the imports from each sector in the total imports of Brazil and South Korea, respectively. This figure shows that the import structure of the two countries is in fact very similar, with only two minor differences. Firstly, Brazil could not reduce the share of Medium-Tech Manufactures imports, which have indeed increased since1984, going back to levels similar to those observed in the 1970s. Secondly, Brazil has managed to reduce its share of Primary Products imports since the second oil crisis and the debt crisis of mid-1980s, while was not capable to do so and in effect increase its share of Primary Products imports since 1996.

It is interesting to note, therefore, that despite the high share of High-Tech Manufactures exports in South Korea, the share of imports from this sector has also been increasing, which highlights two aspects of international trade: (i) the production of High-Tech Manufactures has a significant degree of international interdependency, with different components being produced in different countries; and (ii) there is a tendency towards the diversification of consumption in Medium-Tech Manufactures and High-Tech Manufactures, which contributes to the increase of intra-industry trade.

\subsection{Indicators of economic complexity}

Although the analyses presented in the previous sections are informative, the evolution of diversification and bottlenecks is insufficient to provide a complete explanation for the distinct development trajectories of the two countries.

Confronting the South Korean success with the Brazilian case, as illustrated in Figure 1, the information provided in Figures 4 and 7 highlights how relevant the difference in the population size of the two countries is to understand the great divide of the trajectories of their per capita GDPs. For South Korea, around 30 Medium-Tech Manufactures industries with RCA and around 10 High-Tech Manufactures industries with RCA were enough to generate the impressive increase in per capita GDP portrayed in Figure 1. For Brazil, however, around 25 Medium-Tech Manufactures industries with RCA and around 2 HighTech Manufactures industries with RCA were not enough to promote a parallel increase in per capita GDP. Using the ratio Medium-Tech Manufactures plus High-Tech Manufactures industries with RCA to total population as a basic indicator of the structural change required for development, it is possible to observe that South Korea reached a level (0.81) similar to that of developed countries, such as Canada (0.84) and UK (0.92), while Brazil stayed in a level (0.21) closer to less developed economies, such as Russia (0.15) and Venezuela (0.22).

Figure 12 - Competitive production of mediumand high-tech products and GDP per capita

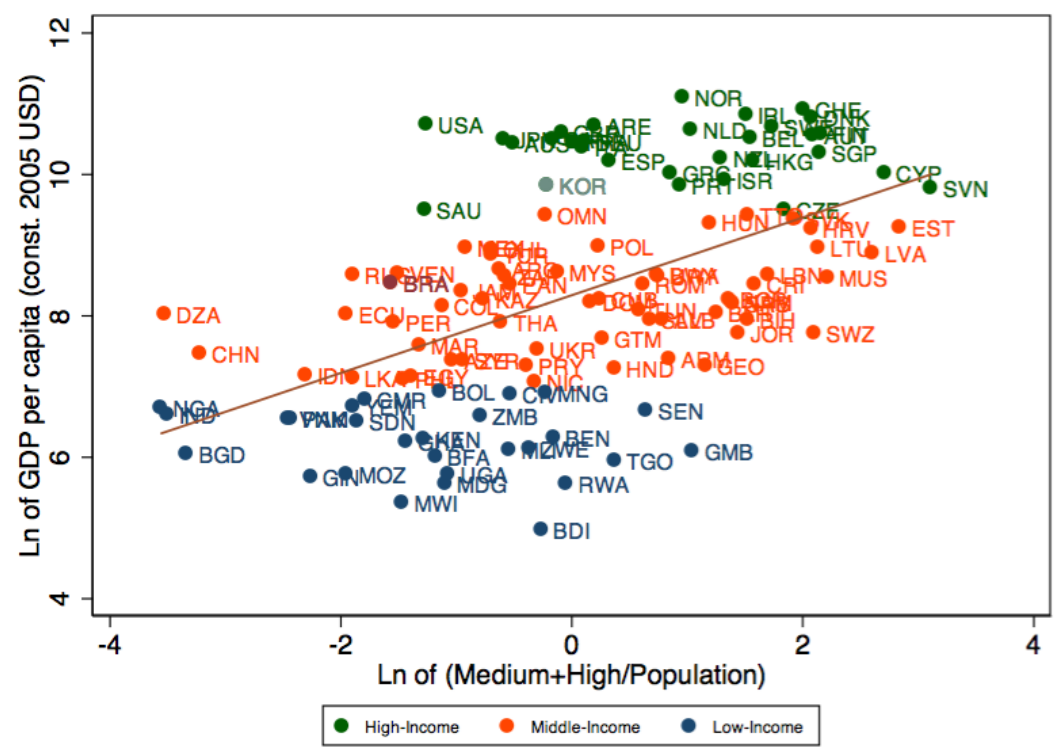

Note: Low-income=under 1045 USD; Medium-income=between 1046 and 12746 USD;

High-income=over 12746 USD. Data used is for the year of 2005.

Source: Authors' elaboration. 
Figure 12 shows how the ratio of medium- and high-tech industries with RCA to population is positively correlated with per capita GDP. Hence, this Figure shows that while South Korea managed to reach a ratio as high as observed in developed countries, Brazil's size required further diversification, and the country's policies were not capable of sustaining this process. As Jacobsson (1993) highlights, the time and costs required for learning to efficiently produce high-tech goods has been increasing through time. Consequently, increasing diversification in these industries becomes more and more difficult through time. Nonetheless, the index presented in Figure 13 is only a partial explanation for the great divide.

Figure 13 uses the index of economic complexity (EC), described in equation (7), to analyse the evolution of the complexity of the Brazilian and the South Korean economies. This figure shows how South Korea and Brazil went through rapid transformations from 1962 to 1975, with the EC of South Korea increasing from -0.01 to 1.1 , and the ES of Brazil increasing from -0.45 to 0.35 . Nonetheless, since the beginning of this process, South Korea's complexity was already much higher than Brazil's. From 1975 to 1992, South Korea experienced a decrease in the complexity of its productive structure (EC of 0.58 in 1992), while Brazil's complexity remained virtually unchanged (EC of 0.38 in 1992). From 1992 onwards, however, South Korea's complexity started to increase rapidly once again, reaching its peak in 2006 (EC of 1.82). This process is a result of the increase of the share of medium- and high-tech exports, which went from $58 \%$ to $69 \%$ during this period, as shown in Figure 7. Meanwhile, although Brazil managed to generate a moderate increase in its complexity until 2000 (EC of 0.68), from then on there has been a dramatic decrease in the country's level of productive complexity, which culminated in a negative EC (-0.29) in 2008. This process of reduction of the economic complexity of Brazil is clearly a reflection of the re-primarization of the economy, as already highlighted in the previous sections, and as reflected in Figure 7, which shows that the share of primary and resource-based exports increased from 49 to $56 \%$ during this period.

Figure 13 - Economic complexity of Brazil and South Korea

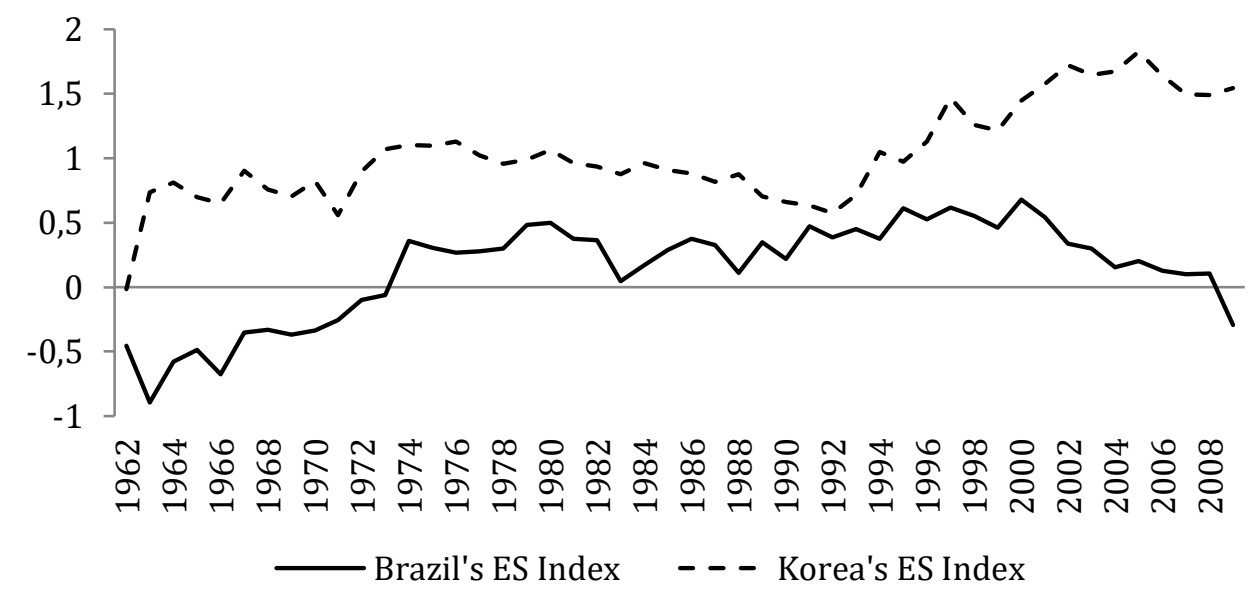

Source: Authors' elaboration.

The combined analysis of Figure 13 with Figure 7 show how changes in export shares that may seem moderate at first can be, in effect, determinant of the country's future development trajectory. In the case of Brazil, an increase of seven percentage points in the share of primary and resource-based exports represented a considerable reduction in the country's complexity, which raises concern about the future development of the economy. In the case of South Korea, an increase of 11 percentage points in the share of medium- and high-tech exports represented a remarkable increase in the country's complexity, which consolidated the country's process of income growth and structural change.

\section{Concluding remarks}

This paper presented an investigation on the reasons why the GDP per capita of Brazil and South Korea diverged so much after 1980. The paper provided two applied contributions to literature. First, by presenting decade-specific product spaces, it highlights changes of the international division of labour and trade as well as each of the countries trade evolution in terms of comparative advantages in products classified by technological-intensity. Secondly, it proposed the adoption of new indexes based on the concept of revealed comparative disadvantage to analyse the performance of the domestic production in the local market vis-à-vis the foreign competitors. 
Most importantly, the paper showed how using indexes of revealed comparative advantage and disadvantage to analyse economies' diversification, bottlenecks and complexity can provide important information to understand development trajectories related to structural change.

The empirical investigation presented in the paper revealed that the development trajectories of Brazil and South Korea can be divided in three distinct periods: (i) from 1962 to 1974: the productive structure of South Korea went through a rapid transformation, with a marked increase in the competitive production of low-tech goods, while Brazil could only produce a significantly smaller change; (ii) from 1974 to 1992: the structural gap between the two countries was reduced. South Korea reduced its diversification while increasing the number of medium- and high-tech industries with RCA, and Brazil increased its diversification while also increasing the number of medium- and high-tech industries with RCA; (iii) from 1992 onwards: South Korea consolidated its structural transformation towards high economic complexity via increasing the share of medium- and high-tech exports, while Brazil was not able to keep the process of structural change and ended up allowing a process of re-primarization that dramatically reduced the complexity of the economy.

The explanation for the distinct trajectories of Brazil and South Korea, however, is found in the policies adopted by the two countries, following their specific historical contexts. The emphasis of South Korea on export led growth associated with the policy of formation of large national conglomerates (the chaebols) was crucial for their success. This strategy led to a sharp move from the production of low-tech to the production of medium- and high-tech manufactured goods, associated with increases in export shares of such goods. Through that process, South Korea managed to reach high levels of complexity and per capita GDP. In contrast, in Brazil, the lack of export promotion led to balance-of-payment deficits that resulted in the debt crisis of 1980s, which eroded the country's capacity to continue the process of structural change necessary for achieving high levels of economic complexity and GDP per capita. The difference in population sizes between the two countries played an important role in the countries' development stories. Due to the much larger population of Brazil in comparison with South Korea, a higher number of mediumand high-tech industries with RCA is necessary to reach high levels of GDP per capita. Consequently, higher costs and effort were necessary to learn to produce a wider variety of such goods with RCA. In the end, therefore, the country could only reach moderate economic complexity, without a high enough number of medium- and high-tech industries with RCA and without a high enough share of exports from these industries.

To conclude, it is important to stress that the indexes discussed in this paper can be an important tool for the design of more effective industrial and technological policies. Firstly, identifying the industries with RCA shows the areas where domestic production is more efficient. Secondly, identifying industries with high product complexity close (in the product space) to industries with RCA provides targets for the development of the economy. Thirdly, combining the information about the industries with RCD and potential to become exporters, with the information about RCA and the proximity between industries provides information about the target industries that are most likely to succeed.

\section{References}

Archibugi, D.; Coco, A. (2005) Measuring technological capabilities at the country level: A survey and a menu of choice, Research Policy, 34, pp. 175-94.

Balassa, B. (1965) Trade liberalization and revealed comparative advantage, Manchester School of Economics and Social Studies, 33, pp. 99-123.

Bahar, D.; Hausmann, R.; Hidalgo, C. (2014) Neighbors and the evolution of the comparative advantage of nations: Evidence of international knowledge diffusion? Journal of International Economics, 92, pp. 111-123.

Boschma, R.; Balland, P.-A.; Kogler, D. F. (2013) Relatedness and Technological Change in Cities: The rise and fall of technological knowledge in U.S. metropolitan areas from 1981 to 2010, Papers in Evolutionary Economic Geography, 13.16, Utrecht University.

Burlamaqui, L; Souza, J. A. P.; Barbosa-Filho N. H. (2006) The Rise and Halt of Economic Development in Brazil, 1945-2004: Industrial Catching-up, Institutional Innovation and Financial Fragility, UNUWIDER Research Paper, 2006/81, United Nations University.

Chang, Ha-Joon. (2006). The East Asian Development Experience - the Miracle, the Crisis and the Future, Penang: Third World Network.

Chung, S. (2011). Innovation, Competitiveness and Growth: Korean Experiences, in: Lin, J. Y.; Pleskovic, B. (Ed). Annual World Bank Conference on Development Economics -Global 2010: Lessons from East Asia and the Global Financial Crisis, Washington, DC: World Bank, pp. 333-357. 
Collins, S. M. (1990). Lessons from Korean Economic Growth, American Economic Review, 80(2), pp. 104107.

Dornbusch, R.; Fischer, S.; Samuelson, P. A. (1977) Comparative Advantage, Trade, and Payments in a Ricardian Model with a Continuum of Goods, American Economic Review, 67(5), pp. 823-839.

Etkowitz, H; Brisolla, S. N. (1999) Failure and success: the fate of industrial policy in Latin America and South East Asia, Research Policy, 28, pp. 337-350

Felipe, J.; Kumar, U.; Abdon, A.; Bacate, M. (2012) Product complexity and economic development, Structural Change and Economic Dynamics, 23, pp. 36-68.

Furtado, C. (1964) Development and Underdevelopment, University of California Press: Berkley (California).

Haggard, S. (2000) The Political Economy of the Asian Financial Crisis, Washington, DC: Institute for International Economics.

Harvie, C.; Lee, Hyun-Hoon (2003). Export-led industrialisation and growth: Korea's economic miracle, 1962-89, Australian Economic History Review, 43(3), pp. 256-286.

Hausmann, R.; Hwang J.; D. Rodrik (2007), What You Export Matters, Journal of Economic Growth, 12(1), pp. 1-25.

Hausmann, R.; B. Klinger (2006), Structural Transformation and Patterns of Comparative Advantage in the Product Space, CID working paper, no. 128.

Hausmann, R.; Hidalgo C.A.; Bustos, S.; Coscia, M.; Chung, S.; Jimenez, J.; Simões, A.; Yildirim, M. A. (2011) The Atlas of Economics Complexity - Mapping Paths to prosperity, Puritan Press: New York.

Hidalgo, C.; Klinger, B.; Barabasi, A. L.; Hausmann, R. (2007) The product space conditions the development of nations, Science, 317, pp. 482-7.

Hidalgo, C; Hausmann, R. (2011) The network structure of economic output, Journal of Economic Growth, 16(4), pp. 309-42.

Hirschman, A. (1958) The Strategy of Economic Development, Yale University Press: New Haven.

Jacobsson, S. (1993) The Length of the Infant Industry Period: Evidence from the Engineering Industry in South Korea, World Development, 21(3), pp. 407-19.

Kuznets, P. (1990) Indicative planning in Korea, Journal of Comparative Economics, 14(4), pp. 657-676

Kuznets, S. (1966) Modern Economic Growth, Yale University Press: New Haven.

Kaldor, N. (1966) Causes of the slow rate of economic growth of the United Kingdom, Cambridge University Press: Cambridge.

Lall, S. (1992) Technological capabilities and industrialization, World Development, 20, pp. 165-186.

Lall, S. (2000) The Technological Structure and Performance of Developing Country Manufactured Exports, 1985-98, Oxford Development Studies, 28(3), pp. 337-69.

Lewis, A. (1955) The Theory of economic Growth, Irwin: Homewood.

Lybbert, T. J.; Zolas, N. J. (2014) Getting patentes and economic data to speak to each other: An 'Algorithmic Links with Probabilities' approach for joint analyses of patenting and economic activity, Research Policy, 43, pp. 530-542.

Ministry of Science, ICT and Future Planning (2013). 2012 Modularization of Korea's Development Experience: The Internalization of Science and Technology in the earlier stage of Economic Development in South Korear Available from: https://www.kdevelopedia.org/mnt/idas/asset/2013/06/17/DOC/PDF/04201306170126736076481.pdf.

Delfim Netto, A. (2005) Meio século de economia brasileira: desenvolvimento e restrição externa, In.: Giambiagi, F.; Villela, A.; Castro, L. B.; Hermann, J. (Orgs.) Economia Brasileira Contemporânea (1945-2004), Elsevier: Rio de Janeiro.

Prebisch, R. (1962) The economic development of Latin America and its principal problems, Economic Bulletin for Latin America, 7, United Nations.

Rostow, W. W. (1958) The take-off into self-sustained growth, In: Agarwala, A. N.; Singh, S. P. (Ed.) The Economics of Underdevelopment, Oxford University Press: London.

Serrano, F.; Summa, R. (2011) Política Macroeconômica, crescimento e distribuição de renda na economia brasileira dos anos 2000, IV Encontro Internacional da AKB.

Woo-Cumings, M. (1999). The State, Democracy, and the reform of the Corporate Sector in Korea, in: Pempel, T. J. (ed). The Politics of the Asian Economic Crisis. Ithaca and London: Cornell University Press, pp. 116-142. 
Zeile, W. (1991). Industrial policy and organization efficiency: the Korean chaebol examined, in: Hamilton, G. (ed). Bussiness Networks and Economic Development in East and Southeast Asia, Centre of Asian Studies, University of Hong Kong, pp. 253-278. 